\title{
QUANDO AS ESCOLAS FECHARAM: LUGAR DA DOCÊNCIA A PARTIR DOS RELATOS DAS PROFESSORAS AOS GRUPOS NA UNIVERSIDADE.
}

\author{
When the schools closed: place of teaching based of teachers' reports to the university \\ groups.
}

\section{Cuando las escuelas cerraron: lugar de enseânza en base a los informes de los maestros a los grupos universitarios.}

\author{
Juliana Fatima Serraglio Pasini ${ }^{1}$ \\ Flavia Anastacio de Paula ${ }^{2}$ \\ Flaviana Demenech ${ }^{3}$
}

\begin{abstract}
Resumo
O trabalho analisa reflexões resultantes do atendimento emergencial em tempos de Pandemia para as ações realizadas pelo grupo de pesquisa vinculado à UNIOESTE, na formação de professores inicial e continuada, articuladas especialmente nas relações sobre a atuação docente no ensino remoto. Ancorada nos estudos de Cunha (2001), Vygotsky (1991) e Guedes-Pinto (2015), tomamos como possibilidade ofertar os projetos de extensão remotos e a partir deles construir grupos focais. Os encontros remotos são reconhecidos, neste texto, como ações que contemplam a formação inicial e continuada dos professores. Como resultados apontamos: o papel da escrita, mediação, reconfiguração do tempo e espaço, professoralidade, o protagonismo, articulação da formação inicial com a formação continuada e aprendizagem significativa, nas escolhas e nos discursos dos participantes nos projetos desenvolvidos.
\end{abstract}

Palavras-chave: Formação de Professores. Pandemia do Covid-19. Ensino Remoto.

\begin{abstract}
The work presents reflections resulting from the emergency care in times of pandemic in the actions carried out by the UNIOESTE Research group linked to UNIOESTE, on initial and continued teacher education, articulated especially in relation to teaching activities, remote teaching. Anchored in the studies by Cunha (2001), Vygotsky (1991) and Guedes-Pinto (2015), we took as a possibility to offer remote extension projects and from them build focus groups. In this text, remote encounters are recognized as actions that contemplate the initial and continuing education of teachers. As results we point out: the role of writing, mediation,

\footnotetext{
${ }^{1}$ Pedagoga pelo UDC, Mestre em Educação pela UNIOESTE-PR, Doutora em Educação pela UNISINOS-RS. Professora Visitante na Universidade Federal da Integração Latino-Americana. Membro do Grupo de Pesquisa MEDIAR. E.mail: jfserraglio@gmail.com ORCID: https://orcid.org/0000-0002-7854-4038

${ }^{2}$ Pedagoga pela UFMG, mestre e doutora pela Faculdade de Educação da Unicamp. Professora Associada da UNIOESTE-PR Campus de Foz do Iguaçu trabalha com as disciplinas de Infancia, Educação Infantil, Alfabetização e Alimentação Escolar. E-mail: flaviaanastaciopaula@gmail.com.br. https://orcid.org/0000-0003-3661-6221..

${ }^{3}$ Pedagoga pela UNIOESTE, campus Foz do Iguaçu, mestre em Educação pela Faculdade de Educação da UPF e doutora em Educação pela Faculdade de Educação da UFPel. Professora Formadora de Professores Pedagogos da Educação Básica do Estado de Mato Grosso - SEDUC/MT. E-mail: flavianademenech@gmail.com ORCID: https://orcid.org/0000-0002-6249-2501.
}

Revista Devir Educação, Lavras-MG. Edição Especial, p.363-383, Set./2021. 


\section{OO DEVIR EDUCAÇÃO}

ISSN: 2526-849X

reconfiguration of time and space, professorship, protagonism, articulation of initial training with continuing education and meaningful learning, in the choices and speeches of the participants in the developed projects.

Keywords: Teacher Education. Covid-19 pandemic. Remote Teaching.

\section{Resumen}

El trabajo analiza reflexiones resultantes de la atención de emergência en tempos de Pandemia por las accines desarrolladas por el grupo de investigación vinculado a UNIOESTE, en la formación docente inicial y continua, articuladas especialmente en las relaciones sobre el desempeño docente em la enseñanza a distancia. Anclado en los estúdios de Cunha (2001), Vygotsky (1991) y Guedes-Pinto (2015), tomamos la posibilidad de ofrecer proyectos de extensión remota y construir grupos focales basados em ellos. En este texto, los encuentros remotos son reconocidos como acciones que contemplan la formación inicial y continua de los docentes. Como resultados señalamos: el papel de la escritura, la mediación, la reconfiguración del tempo y el espacio, la cátedra, el protagonismo, la articulación de la formación inical com la formación continua y el aprendizaje significativo, en las elecciones y discursos de los participantes em los proyectos desarrollados.

Palabras clave: Formación del professorado. Pandemia de COVID-19. Enseñanza remota.

\section{Introdução}

Foi sem aviso. A escola e a universidade fecharam! Foi quase sem aviso. A pandemia parecia distante. Não nos atingiria. Parecia que, àquela distância, onde uma cidade ficava em casa e um hospital seria construído em dez dias, não chegaria a nós. De repente, na Europa, os caixões amontoavam, mas não chegaria a nós. Mas, chegou. A escola e a universidade estavam de fato fechadas. A autoridade sanitária local anunciou: "escolas serão as primeiras a fechar e as últimas a abrir", logo, às universidades, seguiu-se a mesma premissa.

Meados de março (2020), tínhamos a percepção de que seria uma catástrofe densa e rápida como o romper de uma barragem, entretanto, devido ao próprio sucesso da contenção, o movimento foi se tornando devagar e lento. Dessa forma, as escolas e universidades ficaram fechadas por 15 dias. Um recesso. Por um mês. As férias! Organização para o ensino remoto. Dois meses! Já houve greves maiores! Outro bimestre! Retorno em agosto! Não foi possível. Em outubro! Não foi possível. Novembro, escolas e universidades ainda fechadas! Os espaços fecharam! As perguntas mudaram! Para as universidades: como reduzir distâncias? Quais ações necessárias para atender os alunos remotamente? Formação continuada? Quais equipamentos e recursos tecnológicos? Quais plataformas? Quais disciplinas ou projetos serão desenvolvidos para não haver maior exclusão dos acadêmicos? Para as escolas, foram: como manter o vínculo? Cuidados corporais e disciplina dos gestos? 


\section{OO DEVIR EDUCAÇÃO}

ISSN: 2526-849X

Conteúdo? Onde ficaram as crianças? Por quais espaços elas poderiam circular? Com quem? Como a fragilidade dos espaços públicos organizados para a infância se revelou? Como manter contato com as crianças? Quais as perguntas necessárias para compreender e registrar a diversidade de modos de cuidar e educar crianças em uma pandemia longa? O que é uma pandemia? Como as pessoas reagirão? Como as instituições se reorganizarão?

A Organização Mundial da Saúde (OMS) declarou, em 11 de março, que a Covid-19 havia se tornado uma pandemia. Nesse período, o Brasil contava com cerca de 50 casos confirmados, mas o aumento significativo do número de contaminados pelo vírus levou à suspensão das aulas. Em maio, de acordo com a OMS, o Brasil ultrapassou 500 mil casos confirmados e mais de 29 mil óbitos decorrentes da Covid-19.

As escolas fecharam, no estado do Paraná a Deliberação 01/2020 CEE-Paraná instituiu a realização das atividades escolares em regime especial no âmbito do Sistema Estadual de Ensino do Paraná em decorrência da legislação específica sobre a pandemia causada pelo novo Coronavírus - COVID-19 e outras providências. O mesmo documento regulamentou e orientou ainda as instituições em âmbito municipal e privado. Instituiu-se, por meio deste, o ensino remoto, que não se caracteriza nem como ensino EAD, pois não é realizado por tutoria, nem como ensino híbrido, por não combinar os elementos que caracterizam este tipo de ensino. O ensino remoto ficou instituído desde 20 de março de 2020, período oficial de fechamento das escolas, ficando a cargo do professor elaborar suas aulas, garantir que o conteúdo fosse trabalhado, além de garantir, segundo a referida deliberação, o cumprimento de 800 horas letivas estabelecidas pela LDB 9394/1996.

Diante do contexto educacional por ensino remoto, esta pesquisa buscou mapear, registrar e socializar as ações realizadas pelo grupo de Estudos e Pesquisas em Práticas Educativas - MEDIAR da Universidade Estadual, localizada no Oeste do Paraná, para atender os acadêmicos do curso de Pedagogia, os professores das redes municipais e privadas de ensino vinculados ou não ao grupo de pesquisa, a fim de lhes fornecer subsídios teóricos, trocar experiências, compartilhar angústias e/ou criar novas formas de atendimento aos alunos, sejam os da Universidade, sejam os das instituições escolares em meio à pandemia do COVID-19. A investigação se deu em quatro fases: primeira fase, de março a abril; segunda fase, de abril a maio; terceira fase, de maio a junho e a quarta fase, a partir de junho quando a universidade institucionalizou os projetos "guarda-chuva" via ações colegiadas, que serão descritas na sequência.

Revista Devir Educação, Lavras-MG. Edição Especial, p.363-383, Set./2021. 


\section{OO DEVIR EDUCAÇÃO}

ISSN: 2526-849X

Nos encontros previamente agendados com os docentes, angústias e anseios das professoras da Educação Infantil e Ensino Fundamental foram socializados, uma vez que, devido à pandemia, tiveram que se reinventar, criar possibilidades e estratégias para manter o vínculo com seus alunos. Fez-se necessário rever e elencar as novas prioridades para pensar a educação por um viés não conteudista, mas pautado no aspecto dos vínculos humanos que se estabelecem, tanto para as crianças quanto para os estudantes da graduação. Repensar a escola como uma verdadeira rede de apoio às crianças, famílias e professores.

O processo investigativo propiciou registrar e promover reflexões sobre as estratégias de formação continuada do professor, a partir da reflexão que emerge da prática e da profissionalização docente. As categorias de descrição, compreensão e análise dos dados: escrita, mediação, reconfiguração do tempo e espaço, professoralidade, protagonismo e aprendizagem significativa, confirmam a construção teórica delineada a partir dos discursos dos participantes nos projetos desenvolvidos. A investigação iniciou-se com 25 participantes e finalizou com um grupo de 100, não houve evasão. Justifica-se a adesão mediante a centralidade dos temas e das questões guias emergirem das inquietações dos próprios participantes.

Os depoimentos recolhidos dos interlocutores nesta investigação são de grande volume tanto via escrita e assíncrona nos grupos de whatsapp, e fórum no classroom e grupo de facebook, quanto via oral e síncrona durante os encontros remotos. Por essa razão, optou-se por não se transcreverem, neste texto, os depoimentos, mas sobretudo, por trazer a lista de temáticas produzidas nos e para os encontros que eram formuladas durante as interlocuções. Optou-se ainda por assumir a riqueza que os novos elementos trouxeram ao processo de pesquisa, explicitando a possibilidade de tratar do não previsto. Houve a percepção de que as experiências significativas narradas pelas professoras traziam possibilidade de produzir novos encontros e construir novas categorias analíticas ou que, somadas às anteriores, ajudariam a explicitar melhor os dados e compreender o real (CUNHA, 2001). Nesse sentido, os encontros tematizavam solicitações de diálogos, de conversas, de escritas, de inquietações que apareceriam com relativa constância nos debates e eram eleitos como o desejo do próximo encontro.

\section{O papel da universidade e ações desenvolvidas para o ensino remoto emergencial}




\section{QO DEVIR EDUCAÇÃO}

ISSN: 2526-849X

O papel das universidades no mundo ultrapassa a simples tarefa de formar cidadãos para o mercado de trabalho, incluindo, nos planos de ensino institucionais e nas metodologias, o objetivo de formar para o senso crítico e prepará-los para uma sociedade em constante transformação, ainda mais competitiva e capitalista.

A pandemia do COVID-19 instaurou uma situação de excepcionalidade em todo o mundo como o distanciamento social e a tomada de cuidados referentes à segurança sanitária que nos obrigaram a realizar adaptações para a continuidade de nossas atividades laborais. Para a Educação, essas adaptações se tornaram mais complexas ao se assumir o ensino remoto como forma de acesso à educação, expondo as dificuldades das redes públicas no que se refere ao acesso, permanência e oferta de um ensino de qualidade.

A universidade historicamente utiliza a pesquisa para gerar novos conhecimentos e qualificar processos de ensino e aprendizagem. Em meio à pandemia do Covid-19, as universidades públicas, em especial, ofertaram cursos para profissionais de diferentes áreas, realizaram pesquisas, promoveram atividades de grupo de pesquisa, ensino e extensão, cumprindo a sua função social. Nesse momento, as portas das universidades foram abertas, rompendo barreiras e paradigmas, uma vez que não apenas os alunos vinculados aos cursos foram beneficiados, mas também os profissionais em atuação de cada área e membros externos receberam a oportunidade de se qualificarem. Dessa forma, as instituições passaram a responder às necessidades locais e regionais.

Chartterton e Goddard (2003) ao discutir sobre as possíveis respostas das instituições superiores às necessidades regionais, ressaltam que um "terceiro papel" está diretamente relacionado a essa ação, sendo este o grande desafio. Faz-se necessário estabelecer conexões e aproximações, para identificar aspectos de desenvolvimento para a melhoria da qualificação profissional, do desenvolvimento tecnológico, da promoção de outras formas de ensinar e aprender, sem cair na armadilha de se tornar um “[...] espaço predominante e quase exclusivo de formação tanto para o trabalho quanto para outros aspectos da manutenção do próprio modo de produção capitalista" (COLARES, 2020, p. 285-286).

A pandemia nos possibilitou aprender uns com os outros, nos ver, observar a falta de domínio de novos recursos tecnológicos e a emergente necessidade de criar estratégias para atender aqueles sem acesso a meios tecnológicos que resultaram em novas aprendizagens, e exigiram também troca e coletividade. Uma solução encontrada foi a organização de grupos 


\section{OO DEVIR EDUCAÇÃO}

ISSN: 2526-849X

formativos por meio de projetos de extensão, que realmente fizeram a diferença nos diversos contextos. Nesse sentido, Catani (2008) destaca que,

o papel da universidade pública, o tema da universidade, hoje, é um dos mais candentes e de grande relevância social, no sentido de se tentar mostrar que no Brasil, país com uma grande quantidade de alunos envolvidos no ensino desde a base do sistema até o topo, isto é, a educação superior, enfrenta-se um grande problema: cerca de 72 ou $73 \%$ dos alunos encontram-se matriculados em instituições privadas, enquanto apenas 27 ou $28 \%$, o estão em estabelecimentos públicos. A consequência dessa situação é que o Brasil apresenta uma das mais baixas taxas de escolarização bruta da América Latina, no que se refere à educação superior (CATANI, 2008, p. 5)

Lombardi e Colares (2020), no artigo "Escola Pública, projeto civilizatório burguês versus práxis emancipatória", retratam o histórico da institucionalização da escola no Brasil e recuperam aspectos históricos que ressaltam o quão longe ainda estamos de transformar a educação pública democrática, uma vez que "a redução do investimento público, a ampliação da mercadorização e da ação dos grandes conglomerados financeiros nos diferentes níveis educacionais, e a desoneração do Estado para com às políticas sociais públicas se intensificaram com o golpe de Estado de 2016, o governo de Jair Bolsonaro e a pandemia do coronavírus em 2020" (p. 22-23).

As questões relativas às desigualdades no contexto educacional foram evidenciadas pela pandemia. "O desafio da oferta do direito à Educação Básica no Brasil é grande quando se considera mais de $80 \%$ das matrículas concentradas nas redes públicas de ensino", visto que "menos da metade das escolas públicas (46\%) tem acesso a saneamento básico" (OLIVEIRA, 2020, p. 30).

Soares Neto et Al (2013) desenvolveram uma escola de infraestrutura para avaliar o efeito escola e o impacto de fatores contextuais no desempenho escolar brasileiro. Para tanto criaram quatro categorias: elementar, básica, adequada e avançada. Os atores com base nessa escala, realizaram uma análise comparativa de infraestrutura escolar por região do país e por dependência administrativa, na qual constataram que $62,5 \%$ das escolas federais estão nas categorias adequada e avançada, 51,3\% das escolas estaduais estão na categoria básica e $61,8 \%$ das escolas municipais estão na categoria elementar. Considerando que o grosso da oferta da Educação Básica é um estabelecimento de ensino nas redes estaduais e municipais, o estudo demonstra precariedade da oferta para a maioria da população demandante (OLIVEIRA, 2020, p. 30). 
Reafirma-se, com Oliveira, o quão preocupante e complexo é tratar da oferta do ensino não presencial, ao reforçar questões de desigualdade que refletem e impactam o ensino remoto e, ainda, impõem a dificuldade de repensar o retorno das aulas presenciais, tendo em vista não apenas questões concernentes a desigualdades de condições de aprendizagem, mas pelas exigências sanitárias impostas pelo coronavírus para o atendimento presencial dos estudantes.

De acordo com a UNESCO (Organização das Nações Unidas para a Educação, a Ciência e a Cultura), em 16 de março de 2020, mais de 1000 países fecharam suas escolas como medida de contenção do coronavírus. Mais de "776,7 milhões de crianças e jovens foram afetados" (CAMPANHA, 2020, p. 3). No Brasil, em 20 de março do mesmo ano, mais de 5.568 municípios já haviam suspendido as aulas, de acordo com o levantamento da UNDIME (União Nacional dos Dirigentes Municipais de Educação). No estado do Paraná, as aulas foram retomadas remotamente no início de abril, seguindo Deliberação 01/2020 CEEParaná, as possibilidades para realização das atividades não presenciais foram elencadas pelo art. $4^{\circ}$,

As atividades escolares não presenciais são aquelas utilizadas pelo professor da turma ou do componente curricular para a interação com o estudante por meio de orientações impressas, estudos dirigidos, quizzes, plataformas virtuais, correio eletrônico, redes sociais, chats, fóruns, diário eletrônico, videoaulas, audiochamadas, videochamadas e outras assemelhadas (CEE, Deliberação 01/2020).

No estado do Paraná, entre alunos da rede estadual e municipal de ensino, incluindo os da educação especial e os da educação de jovens e adultos, mais de 2 milhões 725 mil 378 alunos tiveram suas aulas suspensas (INEP, Censo Escolar, 2018).

De acordo com a pesquisa da Undime ${ }^{4}$, realizada em setembro de 2020, cerca de $96 \%$ dos municípios optaram pela realização de práticas pedagógicas não presenciais, ou seja, materiais impressos (atividades elaboradas pelas professoras, coordenação, secretarias municipais e livros didáticos), envio de vídeos, áudios e complementação visual aos alunos por meio do WhatsApp, plataformas específicas como aulas em canais de televisão, Google Classroom, entre outras formas de atendimento aos alunos no período de pandemia. Para

\footnotetext{
${ }^{4}$ Pesquisa disponível na íntegra: disponível em:<http://undime.org.br/noticia/10-09-2020-09-48-pesquisa-revelaque-96-das-redes-municipais-de-educacao-estao-realizando-atividades-nao-presenciais-com-os-alunos-durantea-pandemia> Acesso em.: jan./2021.
}

Revista Devir Educação, Lavras-MG. Edição Especial, p.363-383, Set./2021. 


\section{OO DEVIR EDUCAÇÃO}

ISSN: 2526-849X

tanto, é necessário considerar não apenas o número de equipamentos que se tem em cada domicílio, todavia as condições socioeconômicas das famílias, a falta de acesso à internet, o único aparelho celular ser o instrumento de trabalho de um dos familiares, ter mais de um estudante no domicílio, além disso, muitos pais e/ou responsáveis dificilmente conseguiram acompanhar as atividades remotas ou auxiliaram o estudante, dada as condições da vida cotidiana que envolvem sobreviver.

No Brasil, de acordo com a pesquisa realizada pelo TIC Domicílios 2018 do CETIC (Centro Regional de Estudos para o Desenvolvimento da Sociedade da Informação), cerca de $58 \%$ dos domicílios não dispõem de internet. Neste mesmo ano, o país ainda contava com 2,1 milhões de domicílios em que há somente sinal analógico de televisão, o acesso à internet se efetiva com maior número por meio do telefone celular, no entanto, apenas $56,3 \%$ da população possui acesso à banda larga (IBGE, 2020). Esses dados devem ser considerados principalmente no planejamento e forma de como será a oferta do ensino remoto.

Dados que nos fazem refletir o quanto a desigualdade afeta nossos estudantes. Sobretudo, porque ensinar presencialmente não é o mesmo que ensinar virtualmente e muitos professores e instituições não estavam preparadas e tão pouco familiarizadas com ferramentas e recursos tecnológicos que possibilitaram realizar e planejar as aulas remotas ou on-line àqueles que minimamente tinham condições de acesso. Dessa forma, mais de $95 \%$ das redes municipais realizaram ensino não presencial, adotaram a distribuição de materiais impressos, com agendamentos para entrega e retirada na escola pelos responsáveis dos estudantes, e 80\% das redes municipais adotaram aulas gravadas como parte das estratégias (UNDIME, 2020).

Ao encontro das ações desencadeadas pela disseminação do Covid-19, fizeram-se necessárias ações imediatas e emergentes para a garantia dos direitos das crianças e adolescentes. Mediante essas emergências, as universidades públicas, em especial, desenvolveram múltiplas atividades com o objetivo de atender, principalmente, aqueles com menos acesso ao capital intelectual. Para isso, foram criados cursos on-line, plataformas para a formação continuada de professores, inúmeras Lives, e eventos com intelectuais das diversas regiões do país, a fim de contribuir e apoiar os professores e profissionais de diferentes áreas na superação dos desafios impostos pelo coronavírus.

Dentre os desafios, ressaltamos a sobrecarga de trabalho, em específico, dos docentes das diferentes etapas de ensino analisada na pesquisa realizada pelo Grupo de Estudos e Políticas Educacionais e Trabalho Docente (GESTRADO/UFMG), intitulado: "Trabalho 


\section{OO DEVIR EDUCAÇÃO}

ISSN: 2526-849X

docente em tempos de pandemia". A pesquisa abarcou 15.654 professores das redes públicas de ensino no Brasil, foi realizada por meio de questionário pelo Google Forms, no período de 8 a 30 de junho de 2020. A pesquisa apresenta que apenas 28,9\% dos professores respondentes afirmaram possuir facilidade no manejo de recursos tecnológicos para uso em suas aulas e outro dado importante revela que mais de 53,6\% dos professores possuem recursos tecnológicos (computadores, notebooks, tablets, celulares), mas não possuem preparo e suporte técnico para a realização das aulas remotas mediadas por tecnologia.

$\mathrm{O}$ aumento da jornada de trabalho dos professores foi significativa segundo a pesquisa, mediante a necessidade de eles aprenderem a utilizar novos recursos tecnológicos, preparar e elaborar materiais para as aulas on-line, ter que adaptá-los para entregar por meio impresso aos alunos sem acesso a recursos tecnológicos, além do horário de atendimento aos alunos por via telefone, aplicativos e apostila. Esses e vários outros aspectos não mencionados contribuíram para o aumento das horas de trabalho dos professores que atuam em todas as etapas de ensino, principalmente, na Educação Básica (GESTRADO, 2020).

Diante do exposto sobre as novas demandas para o ensino no contexto da pandemia, o papel da Universidade tornou-se ainda mais importante e fundamental no desenvolvimento de ações colaborativas junto aos acadêmicos e profissionais da educação. O grupo MEDIAR, pertencente à Universidade Estadual do Oeste do Paraná - UNIOESTE, organizou redes de formação continuada. Através de reuniões inicialmente com o grupo de pesquisa, e posteriormente com a organização de grupos de extensão e pesquisa, de modo a apoiar e formar uma rede colaborativa de professores, de instituições públicas e privadas de ensino, membros da comunidade externa, pertencentes ou não ao estado do Paraná. O grupo de formação/extensão atualmente é composto por 60 participantes, e, ao longo do ano de 2020, iniciando em abril, foram realizadas diferentes propostas, em que os professores têm se apoiado para amenizar o seu sofrimento diante das dificuldades e angústias impostas pelo coronavírus e o ensino remoto.

\section{Formação e apoio aos professores no ensino remoto emergencial junto aos grupos de extensão e de pesquisa}

O ensino remoto emergencial no âmbito educacional não apenas impôs desafios, contudo, é possível afirmar que agregou possibilidades. Não é de hoje que os professores enfrentam problemas relacionados à valorização da carreira docente, precariedade nas 


\section{OO DEVIR EDUCAÇÃO}

ISSN: 2526-849X

condições materiais do trabalho pedagógico, falta de políticas públicas para formação inicial e continuada de qualidade, entretanto, em meio às demandas vivenciadas, os professores desejavam serem ouvidos e apresentarem propostas para desenvolverem por meio de atividades de extensão das quais fossem protagonistas.

Corrobora-se às proposições de Cunha (2018, p. 8), sobre a fundamental capacidade reflexiva sobre o campo científico por parte dos professores, a ser "aplicado [a capacidade reflexiva] às práticas de ensinar e aprender, a ampliação de diálogo epistemológico e interdisciplinar, ao trânsito entre ciência, cultura e sociedade, bem como às práticas individuais e coletivas tornando mais significativo o trabalho docente".

Neste estudo, optou-se por não apresentar os relatos e discursos dos professores envolvidos nos grupos de extensão, somente as ações desenvolvidas. Buscou-se elucidar a importante e árdua tarefa da formação continuada ao permitir que os participantes realizassem reflexões acerca da própria prática, nos debates e conversas, e relacioná-la ao referencial teórico escolhido; valorizar as dúvidas e questionamentos dos professores, por não se tratar de questões retóricas, mas de inquietações que emergiram do contexto da prática pedagógica, de modo a desenvolver o seu protagonismo e profissionalidade.

O ensino remoto emergencial, proposto pelos órgãos governamentais para garantir o acesso ao ensino em meio à pandemia, em tempo-espaço distinto, requer planejamento específico, materiais apropriados elaborados com conteúdo que atendam a essa estratégia. Nesse aspecto espacial, é diferente o ensino presencial quanto às formas de acompanhar os alunos e, por conseguinte, realizar as atividades necessitaram de adaptações. E como dito, os professores não estavam preparados para essa forma de atendimento. O pensar sobre os aspectos temporais exigem reflexão e busca de novas formas para atender os alunos, as famílias e a comunidade escolar. Para tanto, a proposta dos grupos de extensão esteve relacionada à nova situação espaço-temporal e a ouvir e compartilhar demandas e soluções sobre: Como fazer? O que fazer? De que modo atender os alunos? Como compreender as angústias relacionadas ao fazer as atividades em casa pelos familiares e longe do professor e do fazer coletivo/interativo com os colegas. Sobre essas questões, na sequência, descrevemse fases e temas.

No início de março, quando houve a suspensão das aulas, esta parecia ser uma estratégia passageira, para durar dois meses ou mais, no entanto, tornou-se permanente no atendimento educacional no contexto pandêmico. As propostas desenvolvidas pelos grupos 


\section{OO DEVIR EDUCAÇÃO}

ISSN: 2526-849X

que buscaram identificar os elementos focos de preocupação e soluções encontradas pelas professoras para que, no momento pandêmico vivido, os vínculos com alunos e famílias fossem fortalecidos, serão descritas em quatro fases.

Na primeira fase havia o choque e a negação. Após o estabelecimento em 15 de março da suspensão imediata das aulas, o trabalho oscilava entre extrair informações de jornais ou de pesquisadores específicos, listar ações prioritárias, fazer alterações domésticas sanitárias e organizar o espaço para trabalhar em casa e ouvir as demandas dos estudantes matriculados nos cursos pelos quais éramos responsáveis pessoalmente. As ações para a comunidade externa e ex-alunos eram pontuais e vinculadas aos grupos de notícias de ex-alunos e professoras da Educação Básica. O telefone tocava a qualquer horário. As caixas de mensagens lotavam. As ações não eram coordenadas por interesses, mas sim pela demanda. Eram ações de educação em saúde, ações emergenciais e produção de materiais sínteses sobre as orientações e sua distribuição.

Na segunda fase, a partir de início de abril, havia a necessidade de organizar a escuta e propor algo mais coletivo. Como trabalho individual, foi organizado um projeto de escrita de cartas via correio eletrônico cujo principal objetivo era a manutenção dos vínculos, enquanto no plano do colegiado, iniciou-se um processo de catalogação e busca ativa dos estudantes para a comunicação.

Novos arranjos e mudanças, ao longo da história, fizeram parte da criação e construção da universidade, uma vez que a pandemia trouxe a necessidade de novas mudanças e ações que possibilitaram novas formas de conhecimento, por meio da formação continuada e da criação de condições para que os encontros fossem realizados. A UNIOESTE regulamentou a tramitação e a aprovação de atividades de extensão durante o período de isolamento social, com a Instrução de Serviço n. 003/2020 - PROEX. Nosso grupo vislumbrou nos projetos de extensão uma forma de gerar respostas individuais e coletivas para as dificuldades e necessidades postas

pela pandemia.

O primeiro grupo de extensão intitulado: "Cartas a uma professora: a escrita como organizadora do pensamento, mediação e manutenção de vínculos", realizou seis encontros, um a cada semana, as cartas foram socializadas por e-mail e pelo Google Classroom, entre 25 participantes. Todos organizados com temáticas propostas e elencadas pelo grupo ao término 
de cada reunião. No quadro que segue, apresentamos as questões norteadoras de cada encontro.

Tabela 1: Organização das Temáticas desenvolvidas pelo projeto de extensão: “Cartas a uma professora: a escrita como organizadora do pensamento, mediação e manutenção de vínculos.

\begin{tabular}{|c|c|}
\hline & Questões Norteadoras \\
\hline Encontro 1 & $\begin{array}{l}\text { Elabore uma carta pessoal. Fale de ti. Como a pandemia o afeta na sua vida: dos } \\
\text { intersociais e intrapsíquicos? Responda as réplicas e tréplicas dizendo como a } \\
\text { escrita ajuda na organização do pensamento. }\end{array}$ \\
\hline Encontro 2 & $\begin{array}{l}\text { Elabore uma carta descritiva e um relato. Quem cuida do cuidador e de quem } \\
\text { você cuida? Responda as réplicas e tréplicas elaborando sentimentos, emoções, } \\
\text { descobertas, mediações, aprendizados e vínculos construídos. }\end{array}$ \\
\hline Encontro 3 & $\begin{array}{l}\text { Escreva sobre seus processos de aprendizagem neste período: o que você está } \\
\text { lendo, escrevendo, assistindo, editando, arquivando, registrando, quais rotinas } \\
\text { você tem produzido? Qual a sua lista de atividades? E como você está se } \\
\text { realizando, ou não, com elas. Responda a réplicas de réplicas elaborando escritas } \\
\text { sobre o aprendizado e a função organizativa de rotinas e memórias da escrita. }\end{array}$ \\
\hline Encontro 4 & $\begin{array}{l}\text { Entre em contato virtual e resgate uma amizade na sua turma. Com quem da sua } \\
\text { turma você tem entrado em contato e conseguiu resgatar para as interações? } \\
\text { Responda réplicas e tréplicas elaborando sobre a função comunicativa da escrita. }\end{array}$ \\
\hline Encontro 5 & $\begin{array}{l}\text { Produza esse texto, tire uma fotografia dele, entregue para a pessoa ou instituição. } \\
\text { A proposta de escrita é a seguinte: Quem merece um agradecimento neste período } \\
\text { de pandemia? Sua vizinha que resolveu produzir máscaras e doar? Os cientistas } \\
\text { brasileiros e estrangeiros (quem são eles?) que estão em seus laboratórios } \\
\text { pesquisando uma vacina contra o Covid-19? Os profissionais da saúde, ou os } \\
\text { gestores da saúde do seu município? O faxineiro que continuou recolhendo o } \\
\text { lixo? São muitas pessoas, não é mesmo? A sugestão é que você poderá trabalhar } \\
\text { com vários gêneros (carta pessoal, twitter, e-mail, cartão) e redigir } \\
\text { agradecimentos em português e em outras línguas e enviar para pessoas reais. } \\
\text { Depois tire fotografia do material produzido e me envie para registro da } \\
\text { atividade. }\end{array}$ \\
\hline Encontro 6 & $\begin{array}{l}\text { Escreva em formato de carta um relatório que permita refletir sobre o processo } \\
\text { pedagógico de aprendizado da escrita de cartas. Esse projeto pode ser replicável } \\
\text { com seus estudantes? Qual é o sentido e o significado de trabalhar com textos } \\
\text { autênticos? Qual o sentido de escrever sabendo que o interlocutor é real e irá ler e } \\
\text { responder? Como esse tipo de proposta pedagógica mobiliza ações, mediações, } \\
\text { reflexões, intervenções? Como produzir atividades pedagógicas significativas e } \\
\text { não meras tarefas? Como produzir palavras que cuidam e que curam? O que você } \\
\text { aprendeu sobre escrita e leitura, alfabetização, atividades significativas, } \\
\text { interlocução, intervenção e mediação? }\end{array}$ \\
\hline
\end{tabular}

Fonte: Autoras (2020).

Embora a proposta do encontro 5 fosse para ter apenas três réplicas, ele reverberou por cerca de três meses. Afinal, à medida que os destinatários das cartas as recebiam, também respondiam. Foi interessante perceber essa resposta das professoras e estudantes para com 


\section{OO DEVIR EDUCAÇÃO}

ISSN: 2526-849X

seus alunos da Educação Infantil ou do Ensino Fundamental. A prática da escrita, a dialogia como fundamento do ensino e do aprendizado (GUEDES-PINTO, 2015) nos fizeram produzir tanto textos com sentido, como sentidos para a vida, à clausura, aos afastamentos necessários para a sobrevivência, e mesmo, à criação de vínculos. Foi a partir dos vínculos formados nessa segunda fase e na compreensão de que, de fato, poderíamos produzir encontros reais à distância que nos aventuramos a mudar da "plataforma" analógica e assíncrona das cartas via e-mail para a plataforma on-line e síncrona dos encontros remotos.

Conforme apontado por Vygotsky (1991a e 1991b), as produções escritas a respeito dos percursos e situações pandêmicas revelam o quanto a prática da escrita exige esforços psicocognitivos e pode produzir funções de organização das funções mentais superiores de que são formas de atuação no mundo e portadores de indícios do processo de compreensão da pandemia e de ser estudante e da profissão docente.

$\mathrm{Na}$ terceira fase, organizou-se um projeto de trabalho via plataforma cujo foco era o trabalho com os estudantes e montar grupo de reuniões entres eles, mas, o número de professoras em atuação foi aumentando. Nessa fase, realizou-se o projeto de extensão intitulado: "Perguntas sobre (des)escolarização em contexto de Covid-19". Os encontros foram organizados por questões guias, a maioria excedentes do encontro anterior, de modo a fomentar o debate e as necessidades do grupo. Nesta fase, o grupo aumentou para aproximadamente 50 participantes. Os encontros foram realizados via plataforma do Google Meet, com duração de 4 horas síncronas acrescidas de horas assíncronas de interação em grupo sobre as questões norteadoras apresentadas na tabela 2.

Tabela 2: Questões norteadoras por encontro realizado pelo projeto de extensão: "Perguntas sobre (des)escolarização em contexto de Covid-19"

\begin{tabular}{|l|l|}
\hline Encontro 1 & Questões norteadoras \\
\hline Encontro 2 & $\begin{array}{l}\text { Como sobreviver ao ambiente inóspito? Que perguntas fazer sobre a escola em } \\
\text { tempos de corona? Como ouvir, e produzir palavras e gestos sobre autocuidado, } \\
\text { cuidado coletivo, análise de riscos, prevenção e precaução? Quais perguntas } \\
\text { sobre Autocuidado e cuidado coletivo estão sendo veiculadas? Como lidar com } \\
\text { ambiente inóspito: hiper vigilância, EPI, autocuidado, autorregulação, cautela, } \\
\text { observação, autoeficácia, prevenção e precaução? }\end{array}$ \\
\hline $\begin{array}{l}\text { Perguntas sobre o aprendizado coletivo e as redes de controle social e para onde } \\
\text { encaminhamos os pedidos de ajuda: Como sobreviver em ambientes inóspitos? } \\
\text { Questões institucionais e pessoais. Cuidado de si e coletivo. Identidade } \\
\text { profissional. O que precisamos ensinar para a nova cidadania? Qual o papel dos } \\
\text { professores na arte de ensinar tudo a todos e os novos gestos, atitudes e que } \\
\text { compõe a nova cidadania. }\end{array}$ \\
\hline
\end{tabular}

Revista Devir Educação, Lavras-MG. Edição Especial, p.363-383, Set./2021. 


\section{OO DEVIR EDUCAÇÃO}

ISSN: 2526-849X

\begin{tabular}{|l|l|}
\hline Encontro 3 & $\begin{array}{l}\text { Perguntas sobre o aprendizado coletivo e as redes de controle social e para onde } \\
\text { encaminhamos os pedidos de ajuda: Quais as situações de ensino-aprendizado } \\
\text { coletivo e políticas sociais estamos criando, mantendo oportunizando? Quais os } \\
\text { desafios do Ensino e Aprendizado mediado por tecnologias e as instâncias de } \\
\text { deliberação dos segmentos nos conselhos intersetoriais. }\end{array}$ \\
\hline Encontro 4 & $\begin{array}{l}\text { Perguntas sobre Infância, Alfabetização e Alimentação em contexto de covid-19: } \\
\text { Qual a situação do atendimento às crianças pequenas, redes de proteção, redes de } \\
\text { apoio, possibilidades de auto-organização. Como estamos registrando as ações de } \\
\text { professoras, os dilemas pedagógicos, as angústias sobre Infância, Alfabetização e } \\
\text { Alimentação em tempos de covid. }\end{array}$ \\
\hline Encontro 5, 6 e 7 & $\begin{array}{l}\text { Registro e Escritas Dirigidas de forma assíncrona sobre perguntas e } \\
\text { possibilidades de respostas sobre a escolarização, o ensino e o aprendizado } \\
\text { realizadas em fórum de debate mediados online. Compartilhamento de Leituras } \\
\text { Dirigidas sobre Autocuidado, cuidado, proteção e promoção da Saúde Infantil e } \\
\text { dos profissionais. }\end{array}$ \\
\hline
\end{tabular}

Fonte: Autoras (2020).

A educação como meio de transformação precisa trabalhar com a imprevisibilidade e a capacidade dos sujeitos para continuar aprendendo. Trabalhar com a capacidade de elaborar perguntas com um valor e finalidade, atrelados aos problemas vivenciados, fazer refletir coletivamente sobre as possibilidades e formas de resolução desses desafios, base de reflexão teórico-prática exigida para o exercício da docência.

Para que as transformações eminentes sejam academicamente sustentadas e socialmente construídas, são necessários investimentos intensivos e sistemáticos que dependem, em grande parte, das iniciativas institucionais e das políticas públicas. Certamente, incluem e depende do protagonismo docente que, sem um envolvimento real no processo, não sustenta sua importância. A formação situada no contexto do trabalho se coloca como uma condição fundante da qualidade acadêmica (CUNHA, 2018, p. 9).

Para o grupo, os projetos de extensão tornaram-se um meio de formação de qualidade, envolvendo o protagonismo dos professores na tomada de decisões e escolha das temáticas a serem debatidas nos próximos encontros. As reuniões tiveram como ponto de partida o próprio lugar de trabalho dos professores, exigindo um exercício pessoal e coletivo de profissionalização docente.

A quarta fase foi organizada pelos professores vinculados ao curso de Pedagogia "A educação em tempos da pandemia da Covid-19” do qual o Grupo de Pesquisa MEDIAR fez parte como um subprojeto com grupos de extensão que, ao longo do ano letivo de 2020, 
contou com 60 participantes, dentre eles, acadêmicos e membros externos vinculados a diferentes instituições de ensino e diferentes estados.

$\mathrm{Na}$ fase 4, desenvolvemos o subprojeto intitulado: "Infâncias, infantilezas e educação pandêmica". Nos encontros realizados, houve relatos de professoras e de estudantes de Pedagogia, atividades de formação, oficinas envolvendo diferentes temáticas e conteúdos que auxiliassem as professoras no desenvolvimento de práticas pedagógicas mais lúdicas com suas respectivas turmas. Ao longo dos encontros remotos públicos dos cursos de extensão da universidade, o principal procedimento foi a escuta ativa nas reuniões orientadas por um tema guia ou uma pergunta guia nos encontros coletivos via plataforma Meet. Foram 25 encontros, um projeto com carga horária de 100 horas. As temáticas trabalhadas estão listadas na tabela 3.

Tabela 3: Temáticas trabalhadas no projeto: "Infâncias, infantilezas e educação pandêmica"

1. Infâncias, Infantilezas e a educação Pandêmica: o que sabemos sobre as crianças?

2. Lugares da infância e do brincar na Pandemia: quais espaços tempos sugerir e usar?

3. Como falar sobre o adoecer e o proteger-se com crianças e meus alunos?

4. Como narrar sobre o morrer e o luto com as crianças?

5. A literatura infantil em tempos de pandemia. Quais títulos temos sobre o morrer?

6. Saudades, consolo e cuidado! Qual literatura pode ajudar a compor as aulas remotas?

7. Quais as responsabilidades legais das instituições para com seus funcionários e estudantes em tempos de covid?

8. Práticas Lúdicas Experimentais: Ensino e entretenimento na Pandemia.

9. Implicações das Avaliações em Larga Escala nas Práticas Pedagógicas.

10. Desafios das Mulheres na Pandemia: onde estamos e o que estamos fazendo?

11. Pesquisa em Educação e os desafios de documentar os processos com crianças, professoras e gestores: quais práticas para registrar mini-histórias estão divulgadas?

12. Tanatologia, psicologia e a ansiedade de ser docente em uma pandemia.

13. A criança com necessidades educacionais especiais na pandemia: o que temos receio?

14. Tanatologia, Psicologia e o não adoecer docente.

15. Atendimento à infância em alta vulnerabilidade: como podemos atuar?

16. A origem do universo à formação geológica das Cataratas. Estratégias metodológicas

Revista Devir Educação, Lavras-MG. Edição Especial, p.363-383, Set./2021. 


\section{OO DEVIR EDUCAÇÃO}

ISSN: 2526-849X

17. Tanatologia, Psicologia e saúde mental dos profissionais da educação em pandemia.

18. A estrutura lógico matemática do pensamento infantil e possibilidades de orientação dos familiares.

Fonte: Autoras (2020).

Trabalhou-se um tema por noite, conduzido pelos participantes, que se propuseram voluntariamente, a partir dos quais se organizou o cronograma, e as reuniões foram conduzidas com o auxílio dos pesquisadores responsáveis pelo projeto.

Para a realização das ações dos grupos de extensão foi necessário repensar a organização do tempo e espaço, bem como refletir acerca das rotinas, desempenho dos alunos, registros das atividades, sendo esse um grande desafio. A reconfiguração do tempo e espaço de aprendizagem, nas palavras de Cunha é "compreendido como elementos que aprisionam ou libertam os processos de ensinar e aprender da regulação do currículo tradicional e os conhecimentos e saberes que constituem a formação dos estudantes" (2001, p. 114). Ao realizar essa reconfiguração, os professores apontaram experiências e aprendizagens significativas, que se distanciam das divisões tradicionais do tempo, espaço e currículo; antes regulados pelo trânsito entre a sala de aula, agora virtual, os campos de prática, da pesquisa e da interação tecendo novos conhecimentos ao longo das atividades remotas, das reuniões realizadas no ano pandêmico de 2020.

Antonio Nóvoa (2011) tem afirmado que é preciso trazer a formação para dentro da profissão, isto é, compreender que a base inicial é o ponto de partida para uma formação que se dá por toda a vida. Então não se trata de colocar na formação inicial todo o peso da profissionalidade. Mas sim de defender lugares de formação (CUNHA, 2008) que aliem a prática à teoria, contribuindo para fazer da docência um campo profissional. Não basta saber fazer, é preciso compreender teoricamente por que se faz e às consequências dessas ações como professores (CUNHA, 2018, p. 8).

O deslocar-se para um território não conhecido e novo, inclusive para a universidade, foi grandemente valorizado pelos participantes, por forçarem que outros lugares pudessem ser admitidos formalmente como espaços de ensino e aprendizagem. As experiências das práticas propostas nos permitiram ultrapassar linhas imaginárias, aproximar o conhecimento da prática cotidiana e o conhecimento científico.

$O$ conhecimento - visto de forma global e não dual, local e universal, construído no processo quando articula o conhecimento científico com 


\section{OO DEVIR EDUCAÇÃO}

ISSN: 2526-849X

outras instâncias e formas de conhecimento. Ter a prática como referencial da teoria, e a leitura e a reflexão narrativa como possibilidade de construção de conceitos (CUNHA, 2001, p. 112).

Conceitos e aprendizagens foram construídos ao longo das reuniões dos grupos de extensão, desenvolvidas de junho a dezembro, em destaque, os de compreender e identificar o projeto de extensão como forma de desenvolver propostas para a formação continuada de professores. Os participantes realizaram pesquisa científica, leitura, refletiram acerca do contexto atual, estudaram legislações e mudanças no âmbito educacional, estiveram nas escolas atendendo alunos e famílias que não tinham acesso a recursos tecnológicos com atividades impressas, bem como apoiando alunos e seus familiares no atendimento domiciliar, observaram construções discursivas vindas do senso comum, reconheceram outros saberes. Em diversos momentos, as análises da realidade permitiram encontrar indicadores de que o conhecimento sustentava as experiências colhidas pelos professores, percebe-se que às experiências rompiam "com o paradigma dominante, mesmo que estas indicações se alicerçam num comportamento empírico" (CUNHA, 2001, p.112).

Realizaram-se travessias que enriqueceram a prática pedagógica, construíram saberes que emergiram das relações e conexões entre o conhecimento adquirido e a experiência adquirida no contexto real, compreenderam de que forma os professores podem contribuir para o desenvolvimento de seus alunos mesmo a distância. Identificamos um processo de verdadeira mediação pedagógica, envolvendo o professor, alunos (participantes dos projetos de extensão) e conhecimento. Como definido por Cunha, a mediação

[...] inclui prazer e entusiasmo como elemento chave de recuperação das subjetividades dos envolvidos no processo; elege metodologias interativas como projetos de ação e pesquisa a partir da sala de aula; envolve, como possibilidade, novas tecnologias construtoras de habilidades intelectuais complexas (CUNHA, 2001, p. 112).

Os temas e as propostas desenvolvidas emergiram da relação professor, aluno e conhecimento e, embora as atividades do ano de 2020 findassem, formou-se um único grupo com todos os participantes, pelo WhatsApp, que se mantém ativo, por meio do qual acontecem as aproximações, escuta, debates e diálogos que ocorrem diariamente, conforme novas demandas são listadas pelas professoras em atuação do setor público, privado e pedagogas em formação no curso de Pedagogia da UNIOESTE. Os membros do grupo focal iniciaram uma nova fase de debates acerca de uma nova proposta de projeto de extensão para 


\section{OO DEVIR EDUCAÇÃO}

ISSN: 2526-849X

o ano de 2021, incluindo práticas e subgrupos de estudo nas suas instituições de ensino a que estão vinculados.

Destacam-se, como resultados deste estudo, alguns dos atendimentos e momentos de escuta ativa realizada pelo grupo, composto não apenas por professores da Educação Básica e Superior, mas também por psicólogos, psicopedagogos, nutricionistas, e, com eles, formou-se uma verdadeira rede de apoio e de formação continuada. Os professores foram protagonistas 5 das experiências estudadas e, ao se inquietarem em como atender seus alunos no momento pandêmico, atribuíram novos significados às experiências de formação, revelando assim a necessidade de descobrir novos significados para o exercício da docência.

Os projetos de extensão permitiram criar e valorizar novas formas de aprender, em especial, as vivências, saberes e experiências. "A sociedade está a requerer uma educação superior que se afaste das verdades prescritivas e enfrente a condição da incerteza e da mudança como um valor" (CUNHA, 2018, p. 9). Com acelerado avanço das transformações, não cabe um ensino reforçar a transmissão de conteúdos, como acontecia no ensino tradicional, o professor como transmissor de conteúdos e o aluno passivo no recebimento das informações. É preciso que os profissionais da educação assumam o papel de protagonistas, com propostas que envolvam seus alunos na tomada de decisões, no pensar, refletir e questionar o contexto no qual estão inseridos, além de produzir conhecimento por meio de diferentes propostas que lhes permitam transitar entre o conhecimento historicamente e socialmente produzido e a prática vivenciada.

\section{Conclusão}

Pelo exposto sobre a investigação com relação ao lugar da docência, foi possível socializar as atividades de extensão realizadas para atender os professores em formação inicial e continuada em meio ao ensino emergencial, em decorrência da Covid-19. Esta se configurou no entendimento dos pesquisadores e dos participantes do projeto, como curso de formação continuada ao promover um movimento que rompe os paradigmas do ensino tradicional.

\footnotetext{
${ }^{5} \mathrm{O}$ protagonismo - percebido como a participação do aluno, a tomada participativa de decisões, a produção pessoal e criativa, o estímulo a formas de pensar situadas, construtoras do trânsito entre a teoria e a prática. [...] O protagonismo tem a ver com a superação da concepção construída pela ciência moderna que dicotomizou o sujeito do objeto do conhecimento. [...] O protagonismo também redimensiona a tradicional percepção negativa do erro nos processos de ensinar e aprender porque pressupõe trabalhar com múltiplas possibilidades e o erro faz parte da construção do conhecimento. Esta condição distensiona o aluno e o libera para novas aventuras epistemológicas (CUNHA, 2001, p. 113)
}

Revista Devir Educação, Lavras-MG. Edição Especial, p.363-383, Set./2021. 


\section{OO DEVIR EDUCAÇÃO}

ISSN: 2526-849X

O ensino remoto provocou mudanças e marcas profundas em professores e comunidade escolar de modo geral. É importante destacar que existe um campo científico específico de saberes que precisam ser mobilizados para que as instituições de Ensino Superior possam alcançar sua dimensão política, social e cognitiva (CUNHA, 2018). As instituições precisam realizar um movimento de horizontalidade, como proposto por Nóvoa (2017); Cunha (2018), contribuir com o avanço na condição formativa e demandas advindas da comunidade escolar, respondendo às exigências da universidade no século XXI.

Os textos produzidos desde as cartas escritas até as apresentações e textos orais contêm elementos que trazem informações sobre o papel do ensino e da universidade na medida em que tornam visíveis o diálogo entre estudantes em formação e profissionais em atuação, confirmando o papel dessa relação no processo formativo em andamento. As aulas (lives) e cartas configuram como tempo-espaço de reflexões acerca dos sentidos do que vem a ser professor em período pandêmico, da função social da escola, como encontros privilegiados sobre o que nos acontece e o que compõe a função docente.

As questões guias produzidas não foram questões retóricas advindas de conteúdos estudados ou solicitados, mas emergiram do local de onde estão inseridos os participantes, local que pede respostas de emergências, as quais não podem estar embasadas no senso comum, ao contrário, fundamentadas na mediação entre o conhecimento adquirido e os saberes vivenciados. Desenvolver uma proposta de formação continuada em meio ao ensino remoto, requer considerar a cultura escolar como ponto de partida para a compreensão dos significados atribuídos aos saberes pedagógicos pelos docentes.

As temáticas trabalhadas pelos professores nas oficinas e reuniões reforçam os vínculos identitários com a profissão, os saberes e conhecimentos, envolvendo a reflexão e o movimento entre a teoria e prática, convidando-os a realizar novas travessias.

Ressalta-se que os projetos de extensão são importantes ações que contemplam a formação continuada dos professores, o fortalecimento de vínculos entre professores de diferentes instituições de ensino, a troca de experiências relacionadas ao conhecimento e à vivência e as possibilidades de reflexão da prática pedagógica. Refletir sobre a importância do professor no processo de mediação do conhecimento pedagógico, bem como sobre a função social da escola, principalmente no momento vivenciado pela pandemia do COVID-19, sendo essa uma experiência nunca vivida. Consolida-se a percepção da necessidade do trabalho conjunto de professores em atuação e de professores em formação. A importância da 
compreensão da necessidade de onde estão as crianças, como está sendo a interação com as famílias, o que elas fazem e o que chegam ao ouvido das professoras e assim produzir escutas, produzir palavras, organizar e elaborar sentidos para uma ação.

Debruçar-se sobre as narrativas dos alunos e professores das atividades de extensão, que configuraram a gênese das experiências por eles denominadas como significativas, foi um processo importante de aprendizagem sobre a formação continuada de professores. Não encontramos pesquisas científicas que falem ou apontem os projetos de extensão como proposta formativa para os professores. Esta experiência nos permitiu compreender que os professores avançam no processo de identificar novas configurações do conhecimento como possibilidades de formação que atendam suas expectativas e respondam aos desafios da prática profissional, no qual realmente sejam protagonistas das temáticas e das ações, além de auxiliar no enfrentamento de desafios que terão de experimentar.

\section{Referências}

BRASIL. INEP. Censo Escolar 2018. Brasília/MEC, 2020. .IBGE. Instituto Brasileiro de Geografia e Estatística. PNAD Contínua TIC 2018: Internet chegaa $\mathbf{7 9 , 1 \%}$ dos domicílios do país. Disponível em:<https://agenciadenoticias.ibge.gov.br/agencia-sala-de-imprensa/2013-agencia-denoticias/releases/27515-pnad-continua-tic-2018-internet-chega-a-79-1-dos-domicilios-dopais\#: :text=Acesso\%20\%C3\%A0\%20Internet\%20\%C3\%A9\%20mais,2017\%20(69\%2C8\% 25)> Acesso em: jan./2021.

COLARES, Anselmo Alencar. Empresariamento da Educação. In.: LIMA, A. B. PREVITALI, F. S. LUCENA, C. (Orgs). Em defesa das políticas públicas. Uberlândia, Navegando, 2020.

CUNHA, Maria Isabel da. Aprendizajes significativos en la formación inicial de profesores: un estudio en el área de los Cursos de Licenciatura, Interface _ Comunic, Saúde, Educ, v.5, n.9, p.103-16, 2001.

CUNHA, Maria Isabel da. Docência na Educação Superior: a professoralidade em construção. Educação, v. 41, n. 1, p. 6-11, 29 maio 2018.

CHATTERTON, Paul; GODDARD, John (2003). The response of HEIs to regional needs. In: RUTTEN, Roel; BOEKEMA, Frans; KUIJPERS, Elsa (edited). Economic Geography of Higher Education: Knowledge, infrastructure, and learning regions. London: Routledge. p. $19-41$. 
GUEDES-PINTO, Ana Lucia. Prática de escrita na formação de professores: indícios da apropriação da profissão docente. Campinas -SP. Mercado de Letras. 2015.

LOMBARDI, José Claudinei. COLARES, Anselmo Alencar. Escola pública, projeto civilizatório burguês versus práxis emancipatória. In.: Revista USP. São Paulo, n. 127, p. 11-26. Out./nov./dez.2020.

OLIVEIRA, Dalila. Condições de trabalho docente e a defesa da escola pública: fragilidades evidenciadas pela pandemia. In.: Revista USP. São Paulo, n. 127, p. 27-40. Out./nov./dez.2020.

PARANÁ. Deliberação CEE/CP $\mathbf{N}^{\circ}$ 01/2020. Instituição de regime especial para o desenvolvimento das atividades escolares no âmbito do Sistema Estadual de Ensino do Paraná em decorrência da legislação específica sobre a pandemia causada pelo novo Coronavírus COVID-19 e outras providências. Conselho Estadual de Educação: Curitiba, 2020.

Deliberação CEE/CP N ${ }^{\circ}$ 02/2020. Requerimento apresentado ao Conselho Estadual de Educação do Paraná para a revisão da redação do artigo $2 .^{\circ}$ da Deliberação CEE/CP n. ${ }^{\circ}$ 01/2020 para permitir que o regime especial instituído por essa norma possa ser exercido pelas instituições de ensino que ofertam a Educação Infantil. Conselho Estadual de Educação: Curitiba, 2020.

Deliberação CEE/CP $\mathbf{N}^{\mathbf{0}} \mathbf{0 5} / \mathbf{2 0 2 0}$. Normas para o retorno das aulas presenciais no Sistema Estadual de Ensino do Paraná, no ano letivo de 2020. Conselho Estadual de Educação: Curitiba, 2020.

UNIOESTE. PROEX. Resolução N.003/2020. Cascavel, abril, 2020.

UFMG. GESTRADO. Grupo de Estudos Sobre Política Educacional e Trabalho Docente. Base de Dados. Docência na Educação Básica em tempo de pandemia. Belo Horizonte, UFMG, 2020.

VYGOTSKY, Lev. Pensamento e Linguagem. $3^{\circ}$ ed. São Paulo: Martins Fontes 1991a.

VYGOTSKY, Lev. A formação social da mente. $4^{\circ}$ ed. São Paulo: Martins Fontes 1991b.

Recebido em: 22/07/21

Aprovado em: 28/08/21

Revista Devir Educação, Lavras-MG. Edição Especial, p.363-383, Set./2021. 